\title{
OXIDATION AND REDUCTION OF GLYOXYLATE BY LACTATE DEHYDROGENASE
}

\author{
SHUNJI SAWAKI, NAOOKI HATTORI, NORIYUKI MORIKAWA \\ AND KOZO YAMADA \\ Department of Internal Medicine, Faculty of Medicine, Nagoya \\ University, Showa-ku, Nagoya
}

(Received September 24, 1966)

It has been reported by Meister (1) in 1952 that glyoxylate is reduced by lactate dehydrogenase (E.C. 1.1.1.27.) in mammals. The authors $(2,3)$ confirmed this fact with purified crystalline LDH and with the enzyme extracted from various organs of animals.

Of course glycolate was noted as a reduction product. Zymogram suggested another enzyme to be responsible for the reverse reaction. The authors (4) also reported that glyoxylate was oxidized to oxalate by the action of LDH. This phenomenon is of interest as an evidence to suggest the diversity of enzymatic activity of $\mathrm{LDH}$. The following studies were undertaken to present a few more evidences to prove this possibility.

\section{MATERIALS AND METHODS}

LDH was purified from hog heart extract based on Straub's method (5). Oxidation of $\mathrm{NADH}$ and reduction of $\mathrm{NAD}^{+}$with glyoxylate as a substrate by various $\mathrm{LDH}$ fractions from hog heart was compared with those with pyruvate and lactate. The process of purification is as follows:

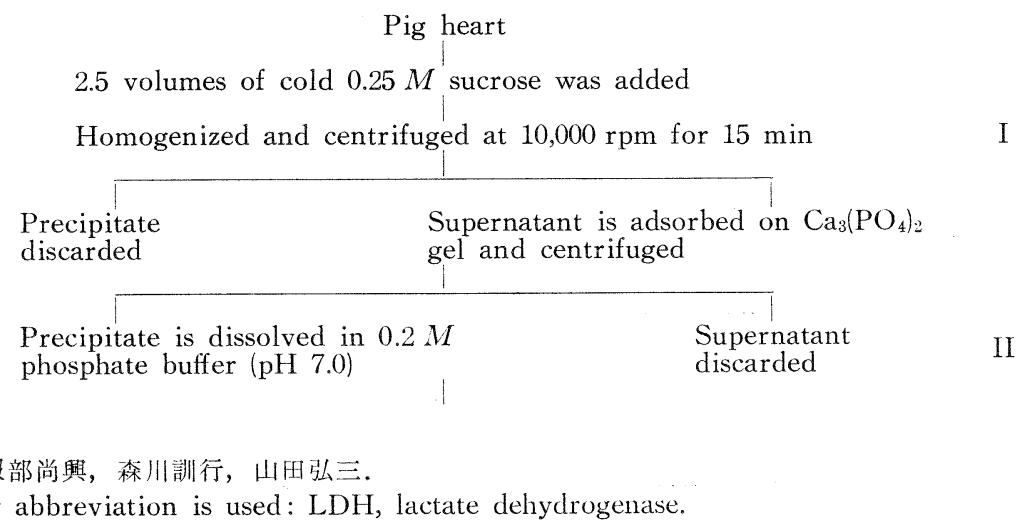




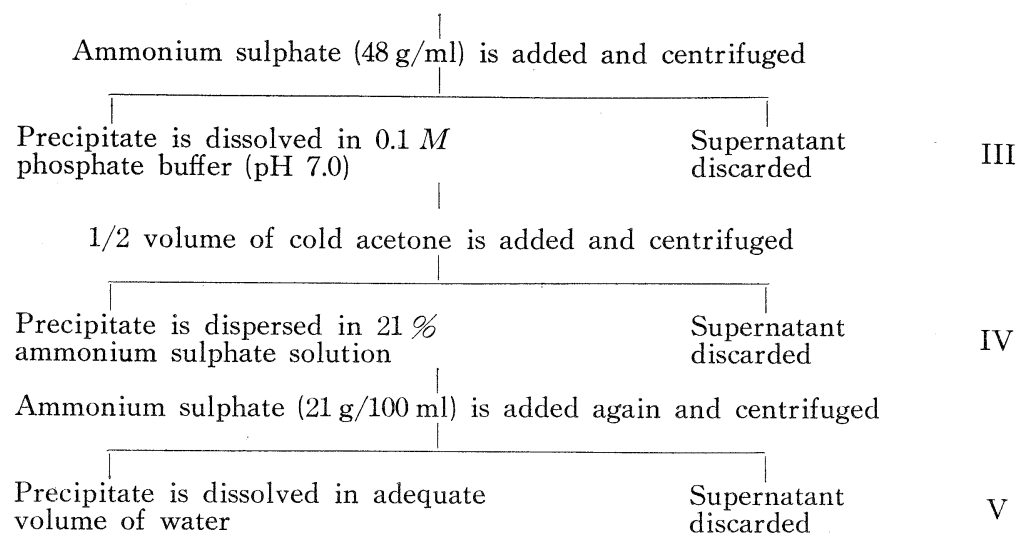

FIG. 1 Purification of LDH from Hog Heart Extract

The amount of enzyme was estimated by the absorbancy at $340 \mathrm{~m} \mu$. The destruction of crystalline LDH (Boehringer) by heat and the ability of substrates to protect against it was studied. The loss of glyoxylate was measured by crystalline glyoxylate reductase from spinach leaves (Boehringer). On the other hand, preparations of subcellular structural components of rat liver were obtained in isotonic sucrose solution, fractionated by Spinco L Ultracentrifuge, and oxidation of $\mathrm{NADH}$ and reduction of $\mathrm{NAD}^{+}$. with glyoxylate as a substrate by the various fractions of the liver were compared with those with pyruvate and lactate according to the method reported previously (4).

\section{RESULTS}

The action of LDH in various fractions of purification from hog heart extract to oxidize and reduce glyoxylate was illustrated in Tables 1 and 2 . In the reduction of glyoxylate and pyruvate the medium was adjusted to $\mathrm{pH} 6.0$ and 7.4 respectively, whereas in oxidation of glyoxylate and lactate $\mathrm{pH} 10.0$ was chosen as the optimal pH. Glyoxylate acted alike lactate or pyruvate in oxidation and reduction by various $\mathrm{LDH}$ fractions, though the ability to reduce glyoxylate was somewhat smaller than that to reduce pyruvate. It is reasonable by the finding that $\mathrm{Km}$ in the former is about $3.5 \times 10^{-3} \mathrm{M}$ and that in the latter $5.9 \times 10^{-5} \mathrm{M}$.

TABLE 1

The Action of Various LDH Fractions from Hog Heart Extract to Reduce Glyoxylate and Pyruvate

\begin{tabular}{ccc}
\hline \hline Stage of purification $a$ & Glyoxylate & Pyruvate \\
\hline I & Decrease of & NADH, emoles $/$ mg $/$ min \\
II & 2.83 & 4.07 \\
IV & 14.16 & 21.90 \\
V & 32.84 & 38.65 \\
\hline
\end{tabular}

a Cf. Fig. 1 . 
TABLE 2

The Action of Various LDH Fractions from Hog Heart Extract to Oxidize Glyoxylate and Lactate

\begin{tabular}{|c|c|c|}
\hline Stage of purification & Glyoxylate & Lactate \\
\hline & \multicolumn{2}{|c|}{ umoles $N A D H$ produced per $m g$ per min } \\
\hline I & 1.45 & 1.38 \\
\hline II & 6.22 & 5.71 \\
\hline IV & 16.00 & 13.05 \\
\hline $\mathrm{V}$ & 39.03 & 34.14 \\
\hline
\end{tabular}

The action of crystalline $\mathrm{LDH}$ to oxidize and reduce glyoxylate was also studied. The amount of residual glyoxylate was estimated by crystalline glyoxylate reductase (containing no $\mathrm{LDH}$ ). The result was summarized in Table 3.

TABLE 3

The Action of Crystalline LDH (M-type) to Oxidize and Reduce Glyoxy'ate

\begin{tabular}{lcc}
\hline & Decrease of glyoxylate & $\begin{array}{c}\text { Decrease or produc- } \\
\text { tion of NADH }\end{array}$ \\
\hline Action to reduce glyoxylate & ⿲moles & $\mu$ moles \\
Action to oxidize glyoxylate & 0.75 & 1.00 \\
\hline
\end{tabular}

Condition for the reaction: $20 \mu \mathrm{g}$ crystalline LDH (M-type) was incubated with $1 \mu M$ $\mathrm{NADH}$ (or NAD) and $1 \mu M$ glyoxylate at $25^{\circ}$ for $1 \mathrm{~min}(\mathrm{pH} 6.0$ for reduction and 10.0 for oxidation). The amount of decrease and production of NADH per minute was measured by the absorbancy at $340 \mathrm{~m} \mu$. The residual glyoxylate was estimated by crystalline glyoxylate reductase after heating at $85^{\circ}$ for 2 minutes.

The decrease of glyoxylate determined by crystalline glyoxylate reductase was roughly comparable to the decrease or production of $\mathrm{NADH}$. The loss of glyoxylate by heating and conversion to formate could not be excluded.

TABLE 4

The Effect of Heat on Crystalline LDH and Protection by Substrates

\begin{tabular}{llc}
\hline & Substrate & Protective action \\
\hline & & $\%$ \\
& - & 0 \\
LDH H-type & Glyoxylate & 25 \\
(Glyoxylate reductase) & Pyruvate & 19 \\
LDH H-type & Glyoxylate & 12 \\
(Glyoxylate oxidase) & Lactate & 11 \\
\hline & - & 0 \\
LDH M-type & Glyoxylate & 14 \\
(Glyoxylate reductase) & Pyruvate & 13 \\
LDH M-type & Glyoxylate & 8 \\
(Glyoxylate oxidase) & Lactate & 8 \\
\hline
\end{tabular}

Condition for the reaction: $100 \mu \mathrm{g}$ crystalline LDH was incubated with $1 \mu M$ substrate and $1 / 15 \mathrm{M}$ phosphate buffer at $55^{\circ}$ and $\mathrm{pH} 7.0$ for $5 \mathrm{~min}$ for LDH (M-type) and at $65^{\circ}$ for $5 \mathrm{~min}$ for $\mathrm{LDH}$ (H-type). The residual activity of the enzyme was measured and compared with that without heating. 
Moreover, destruction of LDH by heating and the ability of substrates to protect against it was investigated. The results are shown in Table 4.

All the substrates added before heating acted protectively against destruction of the enzyme as shown in Table 4.

Fig. 2 shows the zymogram when lactate and glyoxylate were used as the substrates with the subcellular structural components of rat liver. Both substrates showed similar patterns $\left(\mathrm{LDH}_{5}\right.$, the band migrating most negatively).

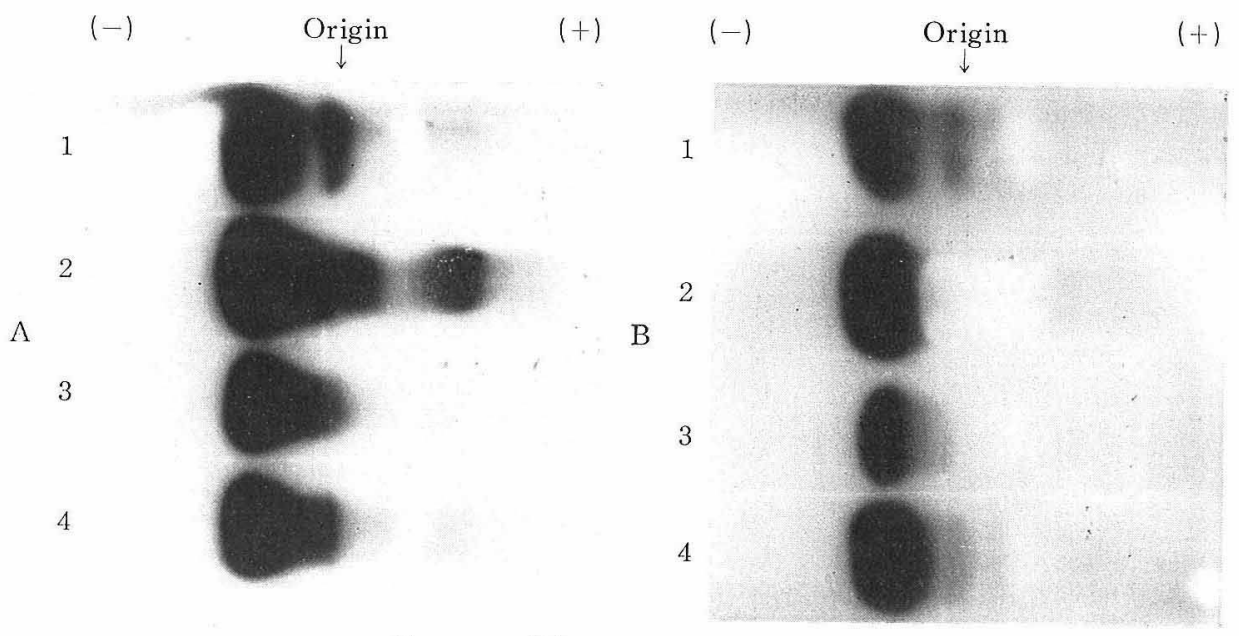

FIG. 2 Photograph of Cellogel

A, developed with lactate dehydrogenase; B, developed with glyoxylate oxidase in rat liver. 1, nuclear fraction; 2, mitochondrial fraction; 3 , microsomal fraction; 4, supernatant.

The protein content of the single fractions was adjusted to a similar level.

The intracellular distribution of the enzymatic reaction (oxidation of NADH) for the two substrates resembled each other, and the ratio of lactate dehydrogenase/glyoxylate reductase was in the range of 1.55 to 1.89 . The results are recorded in Table 5 .

It is evident from these data that LDH plays an important role in mammals in oxidation and reduction of glyoxylate. The authors (6) reported previously that lactate and glyoxylate showed an identical pattern of zymogram. No difference

TABLE 5

Comparison of Lactate Dehydrogenase and Glyoxylate Reductase in Extracts of the Various Fractions from Rat Liver

\begin{tabular}{lcc}
\hline \hline & \multicolumn{2}{c}{ Substrate } \\
\cline { 2 - 3 } & Pyruvate & Glyoxylate \\
\hline & Decrease of $N A D H, \mu$ moles $/$ mg $/$ min \\
Nuclear fraction & 1.36 & 0.80 \\
Mitochondrial fraction & 1.38 & 0.73 \\
Micrsomal fraction & 2.32 & 1.45 \\
Supernantant & 3.71 & 2.38 \\
\hline
\end{tabular}


has been found thus for in various organs examined. The participation of LDH in glyoxylate metabolism is suggested by the similarity in the constitutions of the substrates and also by the recent report by Fishbein et al. (7) who noted that succinic semialdehyde is converted to $\gamma$-hydroxybutyrate by LDH in brain. The causal relation between vitamin $B_{1}$ and $B_{6}$ deficiency and disorder in oxalate metabolism, particularly formation of oxalate stone is another interesting problem to be discussed.

\section{SUMMARY}

1. The action of LDH to oxidize and reduce glyoxylate was confirmed in various fractions of purification from hog heart extract.

2. The action of crystalline $\mathrm{LDH}$ to oxidize and reduce glyoxylate was also studied.

3. The ability of substrates to protect the destruction of crystalline LDH by heating was determined.

4. At each stage of purification of the enzyme in the nuclear, mitochondrial, microsomal fractions and in the supernatant of rat liver, the ratio of activity of the enzyme toward pyruvate (or lactate) and glyoxylate remained constant.

5. It is suggested that $\mathrm{LDH}$ plays an important role in oxidation and reduction of glyoxylate.

\section{REFERENCES}

1. Meister, A., J. Biol. Chem. 197, 309 (1952).

2. Sawaki, S., and Yamada, K., Nature 210, 91 (1966).

3. Yamada, K., Sawaki, S., Hattori, N., Morikawa, N., Proceedings of the Symposium on Chemical Physiology and Pathology 5, 141 (1965).

4. Sawaki, S., Hattori, N., and Yamada, K., J. Vitaminol. 12, 210 (1966).

5. Straub, F. B., Biochem. J. 34, 483 (1940).

6. Sawaki, S., Hattori, N., and Yamada, K., J. Vitaminol, 12, 303 (1966).

7. Fishbein, W. N., and Bessman, S. P., J. Biol. Chem. 239, 357 (1964). 